\title{
Renal Artery Stenosis and Its Predictors in Hypertensive Patients Undergoing Coronary Artery Angiography
}

\author{
Hakimeh Vahedparast ', Mohammad Reza Pourbehi ', Abdullatif Amini ${ }^{2}$, Maryam \\ Ravanipour ${ }^{1,3^{*}}$, Shokrollah Farrokhi ${ }^{3,4,5,6}$, Kamran Mirzaei $^{7}$, Nima Nasehi ${ }^{8}$ \\ ${ }^{1}$ Faculty of Nursing and Midwifery, Bushehr University of Medical Sciences, Bushehr, Iran \\ ${ }^{2}$ Department of Cardiology, Faculty of Medicine, Bushehr University of Medical Sciences, Bushehr, Iran \\ ${ }^{3}$ The Persian Gulf Tropical and Infectious Disease Research Center, Bushehr University of Medical Sciences, Bushehr, Iran \\ ${ }^{4}$ Department of Immunology and Allergy, Medical College, Bushehr University of Medical Sciences, Bushehr, Iran \\ ${ }^{5}$ The Persian Gulf Biomedical Research Institute, Bushehr University of Medical Sciences, Bushehr, Iran \\ ${ }^{6}$ The Persian Gulf Nuclear Medicine Research Centre, Bushehr University of Medical Sciences, Bushehr, Iran \\ ${ }^{7}$ Department of Community Medicine, Faculty of Medicine, Bushehr University of Medical Sciences, Bushehr, Iran \\ ${ }^{8}$ Department of Radiology, Fatemeh Zahra Hospital, Bushehr University of Medical Sciences, Bushehr, Iran
}

A R T I C L E I N F O

Article type:

Article history:

Received: 10 Oct 2010

Revised: 13 Sep 2011

Accepted: 20 Sep 2011

Keywords:

Renal Artery Obstruction

Coronary Artery Disease

Hypertension

Angiography
Original Article

\section{A B S T R A C T}

Background: Renal artery stenosis (RAS) has been increasingly recognized in the recent years, especially in patients with coronary artery disease (CAD). RAS affects the patients with hypertension (HTN), but the exact prevalence is not known.

Objectives: This study was performed to determine the prevalence and to identify the predictors of RAS in hypertensive patients undergoing coronary artery angiography. Patients and Methods: In a cross-sectional study from August 2008 to August 2009, 481 patients with HTN and suspected CAD underwent selective coronary and renal angiography for screening and predicting RAS. RAS was defined as a higher than $50 \%$ stenosis in the renal artery lumen. Multivariate analysis of factors associated with the presence of RAS were examined using a logistic regression model.

Results: The mean \pm standard deviation of age was $59.25 \pm 10.81$ years and $50.3 \%$ were men. According to angiographic data, 425 patients (88.4\%) had CAD, while $56(11.6 \%)$ had normal coronary arteries. RAS was seen in $94(22 \%)$ patients with CAD. The multivariate logistic regression analysis identified only age $(P<0.001)$ and the number of significant coronary lesions $(P<0.001)$ as independent predictors of RAS. Gender, smoking, congestive heart failure, diabetes mellitus (DM), hyperlipidemia (HLP) and body mass index (BMI) were not independent predictors.

Conclusions: This study suggests that in the management of patients with RAS, risk factors should most likely be considered as beneficial. In addition, the clinical and angiographic features are helpful in predicting its presence in elderly patients with CAD.

Copyright $\odot 2011$, Tehran University of Medical Sciences and Iranian Society of Radiology. Published by Kowsar Corp. All rights reserved.

- Implication for health policy/practice/research/medical education:

Understanding the prevalence and predictors of RAS in hypertensive candidates of coronary angiography helps to choose a more precise and cost benefit selection of high risk patients for RAS assessment.

* Corresponding author: Maryam Ravanipour, Faculty of Nursing and Midwifery, Bushehr University of Medical Sciences, Bushehr, Iran. Tel: +98-7714550187, Fax: +98-7714550187.

E-mail: ravanipour@gmail.com

DOI:10.5812/iranjradiol.4553

Copyright $\odot 2011$, Tehran University of Medical Sciences and Iranian Society of Radiology. Published by Kowsar Corp. All rights reserved. 
- Please cite this paper as:

Vahedparast H, Pourbehi MR, Amini A, Ravanipour M, Farrokhi S, Mirzaei K, et al. Renal Artery Stenosis and Its Predictors in Hypertensive Patients Undergoing Coronary Artery Angiography. Iran J Radiol. 2011;8(4):235-40. DOI:10.5812/iranjradiol.4553

\section{Background}

Renal artery stenosis (RAS) is defined as thinning of the renal artery duct. The most common cause of RAS, atherosclerosis, usually involves the main renal artery and the perirenal aorta (1). The prevalence of RAS in the general population is unknown (2). The prevalence of RAS in patients with suspected cardiovascular disorders who have undergone cardiac catheterization was reported as 11.3 to $39 \%$, whereas the RAS with stenosis of more than $50 \%$ has been reported as 6.3 to $28 \%$ (3). Furthermore, RAS affects 1 to $5 \%$ of patients with blood hypertension (HTN), while it is the most common cause of secondary HTN. RAS can occur unilaterally, bilaterally, or in relation to a solitary functioning kidney $(4,5)$. Studies have demonstrated that coronary artery disease (CAD) is one of the most important causes of death in patients with atherosclerotic RAS. In addition, a high prevalence of RAS has been reported in patients with documented CAD $(6,7)$. Contrast angiography is a standard method for the detection of RAS that is readily performed in combination with coronary angiography (8). Therefore, using abdominal aortography concomitant with coronary angiography, a close relationship between the extent of CAD and the severity of RAS has been confirmed $(9,10)$.

Factors associated with the prevalence of RAS are reported as old age, CAD, a higher number of prescribed cardiovascular drugs, HTN, female gender and a previous coronary artery bypass graft (11). Therefore, the early detection and management of RAS, which usually exhibits subtle clinical manifestations, is more important for patients in the presence of unexplained renal insufficiency, refractory HTN, or episodes of unexplained cardiac decompensation.

\section{Objectives}

Due to lack of information about the incidence of RAS and its related risk factors in patients with HTN in the Bushehr population, this prospective study was implemented to determine the prevalence and severity of RAS and its association with predictive variables of atherosclerosis in patients with HTN who are referred for coronary angiography.

\section{Patients and Methods}

\subsection{Study Group}

In a cross-sectional study from August 2008 to August 2009, we prospectively performed selective renal arteriographies in 835 consecutive patients admitted for possible cardiac intervention at the Department of Coronary
Angiography, Bent Al-Hoda Hospital of Bushehr University of Medical Sciences. Before catheterization, a protocol-based clinical examination was used to determine the demographic data, atherogenic risk factors such as diabetes mellitus (DM), HTN, hyperlipidemia (HLP), smoking status and body mass index (BMI). Patients presenting with congenital heart disease or patients hemodynamically unstable during catheterization, known or suspected cases of acute renal failure, patients with a history of contrast nephropathy, patients who were not considered based on the physician's preference and patients who refused or were not able to provide informed consent were excluded from this study. The study was approved by the local Ethics Committee. Written informed consent was obtained from all subjects before any intervention.

We selected patients with HTN and suspected CAD who underwent coronary angiography ( $n=481$ of 835 ). The patients subsequently underwent renal artery angiography via the femoral approach (Seimens, Germany). In this study, the cutoff point used for the definition of RAS and CAD were defined as a higher than $50 \%$ stenosis in diameter which was considered as significant. RAS was independently reported by two interventional cardiologists and assessed by visual estimation as offline. RAS was graded into two groups of normal or less than $50 \%$ stenosis and more than $50 \%$ stenosis. In case of disagreement between the angiographists the patients were excluded from the study.

\section{2. Statistical Analysis}

Demographic and procedural data are expressed as frequency and mean \pm SD. The prevalence and grade of RAS for each group were determined. A binary variable analysis of factors associated with presence of RAS was carried out using a logistic regression model (forward method). $P$ value less than 0.05 was considered significant.

\section{Results}

Of all the 835 hypertensive patients who were candidates for coronary angiography, totally 481 (57.6\%) were included in the study and 354 patients were excluded because of the exclusion criteria. The enrolled patients underwent renal angiography too. Two-hundred forty two of the patients (50.3\%) were male and 239 (49.7\%) were female. According to the demographic data, the patients' risk factors were HLP (43.0\%), DM (30.4\%) and smoking $(41.8 \%)$. Based on the definition of RAS in this study, totally $136(28.3 \%)$ of the patients had RAS while bilateral normal renal arteries or less than $50 \%$ stenosis were identified in 345 (71.7\%) of the screened patients. The mean 
age \pm SD was $59.25 \pm 10.81$ and the age ranged from 33 to 88 years with a mean \pm SD of $57.87 \pm 10.51$ in the normal and $62.73 \pm 10.81$ in the RAS group $(P<0.001)$. The mean \pm SD of BMI in the normal and RAS groups was $26.83 \pm 7.01$ and $26.25 \pm 5.49$, respectively $(P>0.05)$ (Table 1). Significant unilateral RAS was identified in $11.1 \%$, while $17.2 \%$ had significant bilateral RAS. Based on significant stenosis (RAS) in the right or left artery, there were 108 (23.7\%) and $120(22.5 \%)$ patients with RAS in the right or left artery, respectively (Table 2). Our findings from coronary artery angiography revealed that $11.7 \%$ had a normal coronary artery or an artery without stenosis and $10.4 \%$ had less than $50 \%$ stenosis in their coronary vessels, while $18.33 \%$ of the patients had single vessel disease ( $1 \mathrm{VD}), 19.6 \%$ had two-vessel disease (2 VD), 35.4\% had three-vessel disease (3 VD) and $4.2 \%$ had both 3 VD and left main coronary artery (LMCA) disease. In addition, the frequency of RAS regarding the number of the involved coronary arteries was 18 (20.5\%) of the 88 patients with $1 \mathrm{VD}, 27(28.7 \%)$ of the 94 patients with $2 \mathrm{VD}, 62$ (36.5\%) of the 170 patients with $3 \mathrm{VD}$ and nine (45\%) of the patients with LMCA together with $3 \mathrm{VD}$. Bivariate analysis showed that patients older than 70 years $(P<0.001)$ and the number of significant coronary lesions $(P<0.001)$ was significantly associated with the presence of RAS. RAS was not significantly correlated with DM, HLP, high BMI or smoking $(P>0.05)$ (Table 1).

\section{Discussion}

The prevalence of RAS in our study was higher than previous studies, mainly in patients with atherosclerosis in the coronary artery, cerebrovascular or peripheral vascular diseases undergoing abdominal aortography (3). Some investigations have reported that the prevalence of RAS among patients who underwent coronary angiography was usually between $6.2 \%$ and $28 \%$ in Western countries, but there is little information about the prevalence of RAS and its predictors in the Middle East (12). The prevalence of RAS was reported as higher than $20 \%$ in studies among selected patients such as patients

\begin{tabular}{|c|c|c|c|c|c|}
\hline & B Coefficient & $\mathbf{S E}^{\mathrm{a}}$ & $\mathbf{O R}^{\mathrm{a}}$ & Pvalue & $95 \% \mathrm{CI}^{\mathrm{a}}$ \\
\hline \multicolumn{6}{|l|}{ Age, $y$} \\
\hline$<60$ & 1 & & & & \\
\hline $60-69$ & -1.258 & 0.273 & 0.284 & 0.004 & $0.0167-0.485$ \\
\hline$>70$ & -0.843 & 0.0289 & 0.430 & 0.000 & $0.244-0.751$ \\
\hline \multicolumn{6}{|l|}{ Sex } \\
\hline Male & 1 & & & & \\
\hline Female & -0.64 & 0.241 & 0.938 & 0.789 & $0.585-1.504$ \\
\hline \multicolumn{6}{|l|}{$\mathrm{DM}^{\mathrm{a}}$} \\
\hline No & 1 & & & & \\
\hline Yes & -0.081 & 0.260 & 0.922 & 0.775 & $0.553-1.536$ \\
\hline \multicolumn{6}{|c|}{$\mathrm{BMI}{ }^{\mathrm{a}}, \mathrm{kg} / \mathrm{m}^{2}$} \\
\hline$<21$ & 1 & & & & \\
\hline $21-24$ & -0.881 & 0.377 & 0.414 & 0.089 & $0.198-0.868$ \\
\hline $25-29$ & -0.644 & 0.368 & 0.525 & 0.08 & $0.255-1.08$ \\
\hline$>30$ & -0.342 & 0.411 & 0.710 & 0.405 & $0.308-1.589$ \\
\hline \multicolumn{6}{|l|}{ Smoking } \\
\hline No & 1 & & & & \\
\hline Yes & 0.187 & 0.238 & 1.205 & 0.433 & $0.756-1.589$ \\
\hline \multicolumn{6}{|l|}{ HLPa } \\
\hline No & 1 & & & & \\
\hline Yes & 0.052 & 0.246 & 1.053 & 0.833 & $0.651-1.705$ \\
\hline \multicolumn{6}{|l|}{$\operatorname{LVEF}^{a}$} \\
\hline$>50$ & 1 & & & & \\
\hline $30-50$ & 0.246 & 0.622 & 1.303 & 0.671 & $0.385-4.408$ \\
\hline$<30$ & -0.156 & 0.288 & 0.855 & 0.587 & $0.487-1.503$ \\
\hline \multicolumn{6}{|l|}{$\mathrm{CAD}^{\mathrm{a}}$} \\
\hline Normal & 1 & & & & \\
\hline $1 \mathrm{VD}$ & 0.426 & 0.3 & 0.653 & 0.156 & $0.363-1.176$ \\
\hline $2 \mathrm{VD}$ & -0.849 & 0.345 & 0.428 & 0.04 & $0.218-0.842$ \\
\hline $3 \mathrm{VD}$ & -1.067 & 0.361 & 0.344 & 0.003 & $0.170-0.699$ \\
\hline
\end{tabular}

${ }^{a}$ Abbreviations: BMI, body mass index; CAD, coronary artery disease; CI, confidence interval; DM, diabetes mellitus; HLP, hyperlipidemia; LVEF, left ventricular ejection fraction; $\mathrm{OR}$, odds ratio; $\mathrm{SE}$, standard error 
who undergo diagnostic coronary angiography (13). For example, in a study performed by Ebrahimi et al., the incidence of significant RAS was 31\% in patients with HTN (14). In another study conducted by Rimoldi et al., the prevalence of RAS was $8 \%$ after multivariate analysis in hypertensive veterans referred for coronary angiography (15). In addition, Rihal et al. found that $47.2 \%$ of the patients with HTN had RAS, of whom $28 \%$ had less than $50 \%$ stenosis, and $19.2 \%$ had stenosis of $50 \%$ or more (16). However, in our study, the prevalence of RAS in the patients with HTN referred for cardiac catheterization was $28.3 \%$. Consequently, the prevalence of RAS in our study was apparently similar to that reported in the Western nations; whereas, it was higher than that in both Shah et al.'s study performed in Peshawar and a study conducted on Asian populations by Yamashita et al., who found the prevalence of significant RAS as $13 \%$ in Japanese patients with $\operatorname{HTN}(17,18)$. This difference may be explained by location and ethnicity. The high prevalence of RAS may be related to the high prevalence of CAD in the Iranian population, especially in Bushehr; furthermore, there is a high prevalence of risk factors for atherosclerosis in both coronary and renal arteries in this country. The risk factors for RAS are those associated with the development of atherosclerosis in other populations. The prevalence of the condition increases with age, a fact first demonstrated in previous studies undertaken almost half a century ago (19). Moreover, Ozkan et al., found that advanced age and HTN are closely associated with significant RAS and occur more frequently in older individuals (20). In a recent study, based on color Duplex sonography in 269 patients RAS was present in 11\% of the patients in the 50-59 years age group, $18 \%$ in the $60-69$ years and $23 \%$ at the age of 70 years and above (21). The association between old age and RAS in our study was similar to that described in other researches and more studies have shown that patients with significant RAS are older (22-24). Here, there is a strong and independent relation between old age and RAS which shows a later or slower start of atherosclerosis in renal arteries rather than the coronary or other peripheral vascular atheroscleroses (25). Although they met the enrollment criteria, we detected RAS infrequently among individuals less than 60 years of age. This observation has important practical implications for cardiac catheterization based RAS screening. The major clinical predictors for RAS are advanced age, multiple coronary artery disease, poorly controlled HTN and renal insufficiency (26). In our study, a strong relationship

\begin{tabular}{|c|c|c|}
\hline & \multicolumn{2}{|c|}{ Renal Artery Stenosis Condition } \\
\hline & Normal or $<50 \%$ Stenosis $(n=345)$ & Renal Artery Stenosis $(\mathrm{n}=\mathbf{1 3 6})$ \\
\hline \multicolumn{3}{|c|}{ Age, y, No. (\%) } \\
\hline$<60$ & $189(55.3)$ & $51(37.5)$ \\
\hline $60-69$ & $101(29.5)$ & $39(28.7)$ \\
\hline$>70$ & $52(15.2)$ & $46(33.8)$ \\
\hline \multicolumn{3}{|c|}{ Gender, No. (\%) } \\
\hline Male & $174(50.4)$ & $68(50)$ \\
\hline Female & $171(49.6)$ & $68(50)$ \\
\hline \multicolumn{3}{|c|}{ BMI $^{\mathrm{a}}, \mathrm{kg} / \mathrm{m}^{2}$, No. (\%) } \\
\hline $21<$ & $31(9.3)$ & $20(15.6)$ \\
\hline $21-24$ & $115(34.5)$ & $38(29.7)$ \\
\hline $25-29$ & $122(36.6)$ & $43(33.6)$ \\
\hline$>30$ & $65(19.5)$ & $27(21.1)$ \\
\hline \multicolumn{3}{|c|}{ Diabetes Mellitus, No. (\%) } \\
\hline No & $237(68.7)$ & $98(72.1)$ \\
\hline Yes & $108(31.3)$ & $38(27.9)$ \\
\hline \multicolumn{3}{|c|}{ Smoking, No. (\%) } \\
\hline No & $194(56.2)$ & $83(63.2)$ \\
\hline Yes & $151(43.8)$ & $50(36.8)$ \\
\hline \multicolumn{3}{|c|}{ Hyperlipidemia, No. (\%) } \\
\hline No & $191(55.4)$ & $83(61)$ \\
\hline Yes & $154(44.6)$ & $53(39)$ \\
\hline \multicolumn{3}{|c|}{$\begin{array}{l}\text { Renal artery stenosis } \\
\text { condition, No. (\%) }\end{array}$} \\
\hline Right & $367(76.3)$ & $114(23.7)$ \\
\hline Left & $373(77.5)$ & $108(22.5)$ \\
\hline Both & $344(71.7)$ & $136(28.3)$ \\
\hline
\end{tabular}

\footnotetext{
a Abbreviation: BMI, body mass index
} 
between RAS and the number of coronary artery lesions was found. However, this finding was expected considering the high prevalence of RAS in hypertensive patients undergoing angiographic procedures for CAD. De Carvalho found that $74 \%$ of patients with RAS had concurrent CAD in one or more coronary arteries, although they had no symptoms of coronary insufficiency (6). In addition, Ollivier et al. reported that among 650 patients suffering from CAD, 94 presented with RAS, corresponding to an estimated prevalence of $14.5 \%$, including $6 \%$ of patients with left coronary artery stenosis, 5.4\% with right coronary artery stenosis, and 3.1\% with bilateral stenosis (26). In addition, the results of medical records of consecutive patients who underwent coronary angiography showed that multi vessel CAD was more frequent in patients with significant RAS (23). However, the relationship between the number of significant coronary lesions and the prevalence of RAS was complex and unclear. Based on angiographic studies, it is commonly accepted that when the number of diseased coronary arteries increases, RAS would probably increase $(12,23,27)$. In our study, abnormal renal angiographies were found to have no relationship with smoking, gender, BMI, DM, ejection fraction (EF), or HLP. In contrast, some studies showed that there were no significant atherosclerosis risk factors $(26,28)$. Therefore, it seems that risk factors for the development of atheromatous changes in renal arteries may be different from conventional CAD risk factors, and the detection of risk factors is important because RAS is a progressive disease and may lead to end-stage renal failure.

The high prevalence of RAS in coronary vascular patients with HTN that are undergoing coronary angiography, especially those with 2 VD or 3 VD, shows HTN to be a predictive finding for RAS in HTN patients. On the other hand, according to the prevalence of RAS in developing countries, renal angiography after coronary angiography may be helpful in finding unknown RAS, and could be of assistance in the treatment of patients.

\section{Acknowledgments}

Support for this study was provided by Bushehr University of Medical Sciences. The authors thank the nursing staff and physicians of the angiography unit at Bent Al Hoda Hospital for their assistance. They also thank Dr Majid Assadi for his helpful comments.

\section{Financial Disclosure}

None declared.

\section{Funding/Support}

The study has been supported by a grant from Bushehr University of Medical Sciences.

\section{References}

1. Balk E, Raman G, Chung M, Ip S, Tatsioni A, Alonso A, et al. Effectiveness of management strategies for renal artery stenosis: a systematic review. Ann Intern Med. 2006;145(12):901-12.
2. White CJ. Catheter-based therapy for atherosclerotic renal artery stenosis. Prog Cardiovasc Dis. 2007;50(2):136-50.

3. Alhaddad IA, Blum S, Heller EN, Beato MA, Bhalodkar NC, Keriaky $\mathrm{GE}$, et al. Renal artery stenosis in minority patients undergoing diagnostic cardiac catheterization: prevalence and risk factors. $J$ Cardiovasc Pharmacol Ther. 2001;6(2):147-53.

4. Haller C, Keim M. Current issues in the diagnosis and management of patients with renal artery stenosis: a cardiologic perspective. Prog Cardiovasc Dis. 2003;46(3):271-86.

5. Shetty R, Amin MS, Jovin IS. Atherosclerotic renal artery stenosis: current therapy and future developments. Am Heart $J$. 2009;:158(2):154-62.

6. Cardoso de Carvalho F, Bregagnollo E, Santos Silva V, Brunie A, da Silva Franco RJ, Martin LC, et al. Frequency of coronary artery disease in patients with renal artery stenosis without clinical manifestations of coronary insufficiency. Am J Hypertens. 2006;19(11):1125-8.

7. Gross CM, Kramer J, Waigand J, Luft FC, Dietz R. Relation between arteriosclerosis in the coronary and renal arteries. Am J Cardiol. 1997;80(11):1478-81.

8. Buller CE, Nogareda JG, Ramanathan K, Ricci DR, Djurdjev O, Tinckam KJ, et al. The profile of cardiac patients with renal artery stenosis. J Am Coll Cardiol. 2004;43(9):1606-13.

9. Aqel RA, Zoghbi GJ, Baldwin SA, Auda WS, Calhoun DA, Coffey CS, et al. Prevalence of renal artery stenosis in high-risk veterans referred to cardiac catheterization.J Hypertens. 2003;21(6):1157-62.

10. Przewlocki T, Kablak-Ziembicka A, Tracz W, Kopec G, Rubis P, Pasowicz M, et al. Prevalence and prediction of renal artery stenosis in patients with coronary and supraaortic artery atherosclerotic disease. Nephrol Dial Transplant. 2008;23(2):580-5.

11. Weber-Mzell D, Kotanko P, Schumacher M, Klein W, Skrabal F Coronary anatomy predicts presence or absence of renal artery stenosis. A prospective study in patients undergoing cardiac catheterization for suspected coronary artery disease. Eur Heart J. 2002;23(21):1684-91.

12. Ghaffari S, Sohrabi B, Siahdasht RB, Pourafkari L. Prevalence and predictors of renal artery stenosis in hypertensive patients undergoing coronary angiography. Hypertens Res. 2009;32(11):100914.

13. Jaff MR. Hypertension and renal artery stenosis: a complex clinical scenario.J Am Osteopath Assoc. 2000;100(10 Su Pt 2):S5-9.

14. Tumelero RT, Duda NT, Tognon AP, Thiesen M. Prevalence of renal artery stenosis in 1,656 patients who have undergone cardiac catheterization. Arq Bras Cardiol. 2006;87(3):248-53.

15. Rimoldi SF, de Marchi SF, Windecker S, Meier B, Allemann Y. Screening renal artery angiography in hypertensive patients undergoing coronary angiography and 6-month follow-up after ad hoc percutaneous revascularization.J Hypertens. 2010;28(4):8427.

16. Rihal CS, Textor SC, Breen JF, McKusick MA, Grill DE, Hallett JW, et al. Incidental renal artery stenosis among a prospective cohort of hypertensive patients undergoing coronary angiography. Mayo Clin Proc. 2002;77(4):309-16.

17. Yamashita T, Ito F, Iwakiri N, Mitsuyama H, Fujii S, Kitabatake A. Prevalence and predictors of renal artery stenosis in patients undergoing cardiac catheterization. Hypertens Res. 2002;25(4):5537.

18. Shah SS, Noor L, Sawar S, Awan ZA, Hafeezullah M, Khan SB, Frequency and predictors of renal artery stenosis in patients with coronary artery disease. J Ayub Med Coll Abbottabad. 2010;22(1):121-4.

19. Schwartz CJ, White TA. Stenosis of Renal Artery: An Unselected Necropsy Study. Br Med J. 1964;2(5422):1415-21.

20. Ozkan U, Oguzkurt L, Tercan F, Nursal TZ. The prevalence and clinical predictors of incidental atherosclerotic renal artery stenosis. Eur J Radiol. 2009;69(3):550-4.

21. Coen G, Calabria S, Lai S, Moscaritolo E, Nofroni I, Ronga G, et al. Atherosclerotic ischemic renal disease. Diagnosis and prevalence in an hypertensive and/or uremic elderly population. BMC Nephrol. 2003;4:2.

22. El-Mawardy RH, Ghareeb MA, Mahdy MM, Sabet SS, Nammas WM. Prevalence and predictors of renal artery stenosis in hypertensive patients undergoing elective coronary procedures.J Clin Hypertens (Greenwich). 2008;10(11):844-9. 
23. Dzielinska Z, Januszewicz A, Demkow M, Makowiecka-Ciesla M, Prejbisz A, Naruszewicz M, et al. Cardiovascular risk factors in hypertensive patients with coronary artery disease and coexisting renal artery stenosis. J Hypertens. 2007;25(3):663-70.

24. Elkohen M. [Screening of renal artery stenosis: which patients, by what methods?]. Rev Prat.1996;46(9):1091-5.

25. Islam MS, Mahmood M, Haque KS, Siddique AM, Banerjee SK, Islam MN, et al. Study of angiographic association of atherosclerotic renal arterystenosis with coronary artery disease in Bangladesh. Uni Heart J. 2008;4(2):24-7.

26. Ollivier R, Boulmier D, Veillard D, Leurent G, Mock S, Bedossa
$\mathrm{M}$, et al. Frequency and predictors of renal artery stenosis in patients with coronary artery disease. Cardiovasc Revasc Med. 2009;10(1):23-9.

27. Rigatelli G, Roncon L, Rinuncini M, Giordan M, Bedendo E, Panin $\mathrm{S}$, et al. Angiographic characteristics of renal arterial disease over the spectrum of coronary artery disease. Am J Nephrol. 2005;25(2):116-20.

28. Cohen MG, Pascua JA, Garcia-Ben M, Rojas-Matas CA, Gabay JM, Berrocal DH, et al. A simple prediction rule for significant renal artery stenosis in patients undergoing cardiac catheterization. Am Heart J. 2005;150(6):1204-11. 